\title{
President's Message
}

This will be my last contribution to the $E H R$ in the capacity of National President as I complete my second term in January 2019 and pass the torch to Kari Engele-Carter. The highlight of my time in office was the ability to contribute to the implementation of two important membership initiatives that were several years under construction. One is the mandatory membership initiative that links membership in CIPHI to the ongoing use of the $\mathrm{CPHI}(\mathrm{C})$ qualification. The other is the enforcement of the requirement that regular members maintain and grow their professional competencies by complying with the Continuing Professional Competency Program. This requirement has been in place since 2010, and commencing in 2019 a progressive enforcement approach will be used to ensure all members can achieve compliance.

It is important for Certified Public Health Inspectors (Canada) to understand that these enhancements are intended for the betterment of the profession and to allow Environmental Public Health Professionals to be held to the same standards and receive the same recognition that other health professionals enjoy. This is what CIPHI "does for you" and what it will continue to do into the future. The battle to be recognized as valued and unique professionals by the public and employers continues. There is still much to be done to promote, enhance, and improve on the work done by many dedicated $\mathrm{CPHI}(\mathrm{C})$ on all our behalves over the last 100 plus years.

All associations run by volunteers face the same recruitment challenges and must be realistic about the amount of work they can undertake with the resources they have. At the same time,

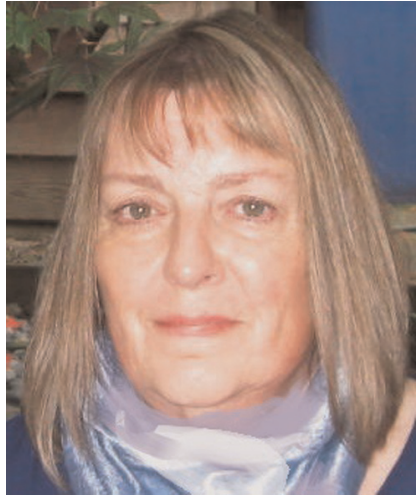

I never stop being amazed at what can be accomplished and at the variety of skills and ideas that new recruits and seasoned volunteers bring to the table. Case in point was our September 2018 Annual Education Conference (AEC) in Saskatoon. When it seemed that this would be the first year in decades without a national conference, a small group of volunteers from across Canada led by members of the National Executive Council (NEC) and in partnership with the CIPHI Office pulled it off in a matter of months. Yes, attendance was modest compared with previous AECs-but the quality was not compromised. There was a strong message from registrants that the conference met its objectives and provided excellent opportunities to build competencies. Many people felt that the smaller number of attendees actually enhanced opportunities to network and engage in relevant discussions with other professionals and exhibitors. It would be an understatement to say the outcome of this event exceeded the NEC's expectations! Discussion is underway regarding the viability of a 2019 AEC, so stay tuned.

I would like to take this opportunity to thank all the clever, kind, and dedicated people involved with CIPHI activities on a national and provincial level who have supported me and worked collaboratively with me during my four years as National President. I am a better person for my association with you all and I look forward to continuing to stay engaged with CIPHI in some capacity and have our paths cross again.

Ann Thomas National President CIPHI 


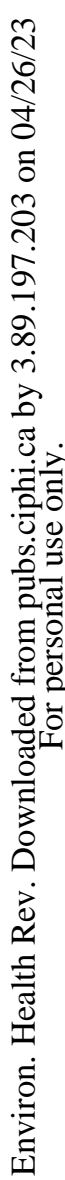

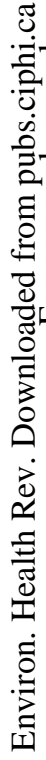

D

छี 